\title{
NUMERICAL SIMULATION OF COMPOSITE REINFORCED BY SPUN THREAD KNITTED FABRIC
}

\author{
Umesh H. Vavaliya, Jemish Modi, Olga Kononova \\ Riga Technical University, Latvia \\ umesh-haribhai.vavaliya@rtu.lv, olga.kononova@rtu.lv
}

\begin{abstract}
The paper focuses on the numerical simulation to predict the stress - strain analysis and elastic parameters of composite materials reinforced by knitted fabric. Due to the symmetrical and repeating distribution of thread loops, instead of focusing on entire fabric, we can form and analyse a generalized structure called unit cell in order to use less complex computer programming. Numerical simulation in Solidworks is done on the unit cell with given boundaries conditions and assumptions to determine the elastic properties of the composite unit cell. A comparative study is also done by using T300 Carbon fiber thread and SY11/1 Steel thread and Hybrid T300 - SY11/1 thread with epoxy as the matrix material with elastic modulus of 4GPa. Valid geometric representations of loops are created by the Leaf and Glaskin Model. The effect of single and multi-thread on the elastic properties of composite material are determined. The resulted elastic properties of composite materials have shown that hybrid threads can be a better reinforcement for composite material with highest modulus of elasticity of 9.35GPa. While single T300 Carbon fiber thread has higher elastic modulus of 8.48GPa compared to SY11/1 steel fiber of 6.09GPa. The addition of Hybrid T300 - SY11/1 reinforcement in epoxy improves the elastic modulus and mechanical strength, while reducing the weight, making it the first choice of selection over other metals and alloys.
\end{abstract}

Keywords: Knitted fabric, elastic modulus.

\section{Introduction}

Nowadays, composite materials with textile reinforcement have been used in different engineering applications due to their relatively low fabrication technology cost. In a range of novel structural applications, textile reinforced composites may replace numerous currently used metallic products. Simultaneously, in many cases, textile reinforced composites are also competitive with traditionally fabricated composites which use the prepregging, layers stacking and autoclave manufacturing methods. Layered composites are performing relatively low tensile and shear strength in thickness direction leading to low wearability, impact resistance and sometimes damage tolerance. All these problems can be solved replacing them by $3 \mathrm{D}$ textile reinforced composites.

One of the promising directions in textile reinforcing is the knitted fabric-reinforcement technology. Interest in polymer and brittle (concrete, ceramics) matrix composites, reinforced by such fabrics increased recently [1-4]. As one of the major advantages of such technology can be mentioned the possibility to produce complex shape products without having flanks in reinforcement at the stage of material fabrication. That feature follows from the loose structure of looped material, which permits the fabric easily to have the relatively large stretch deformation sand to adapt the complicated form shapes [5], [6].

In general, two types of knitting can be exploited. Warp and weft knits can be used as the composite material reinforcement, having enhanced properties in certain directions. In general terms, the weftknitted structures can be marked as more preferred in developmental work, owing to their superior formability.

In the present work, a composite material having weft-knitted reinforcement will be under investigation. Such materials are exhibiting high energy absorption and impact resistance. Thread loops are arranged in structures. Contrary to the woven fabric in the case of a knitted fabric, strands are forming loops. Fabric is highly deformable in all directions. The reason is - threads are not making any straight line anywhere in the material. Several studies have analyzed the geometrical parameters of knitted structures: models of Leaf and Glaskin [7], Munden [8], Kawabata [9] and Choi [10]. The model of Leaf and Glaskin was used in this study.

The carbon and steel threads are used for composite material reinforcement. Numerical simulation of mechanical properties is based on averaging procedures used in combination with some assumptions about the internal structure of the reinforcing fabric [11-13]. 


\section{Numerical simulation of composites}

The geometric description of the thread in the knitted fabric is determined by the use of the Leaf and Glaskin Model. According to Leaf and Glaskin (1955) [7], the structural geometry of the fabric can be defined if three geometric parameters, the wale number $\mathrm{W}$, the course number $\mathrm{C}$ and the thread diameter $d$ are given. The wale number can be described as the step of fabric's loops per unit length along the width (in the course) direction, and the course number can be described as the step along the length (in the wale direction).

CAD software was used to generate the geometrical unit cell of the knitted fabric model and SOLIDWORKS software was used to create the numerical model based on FEM. Due to the symmetrical and repeating distribution of thread loops, instead of focusing on entire fabric, the unit cell is analysed, as shown in Fig.1, in order to use less complex computer programming.
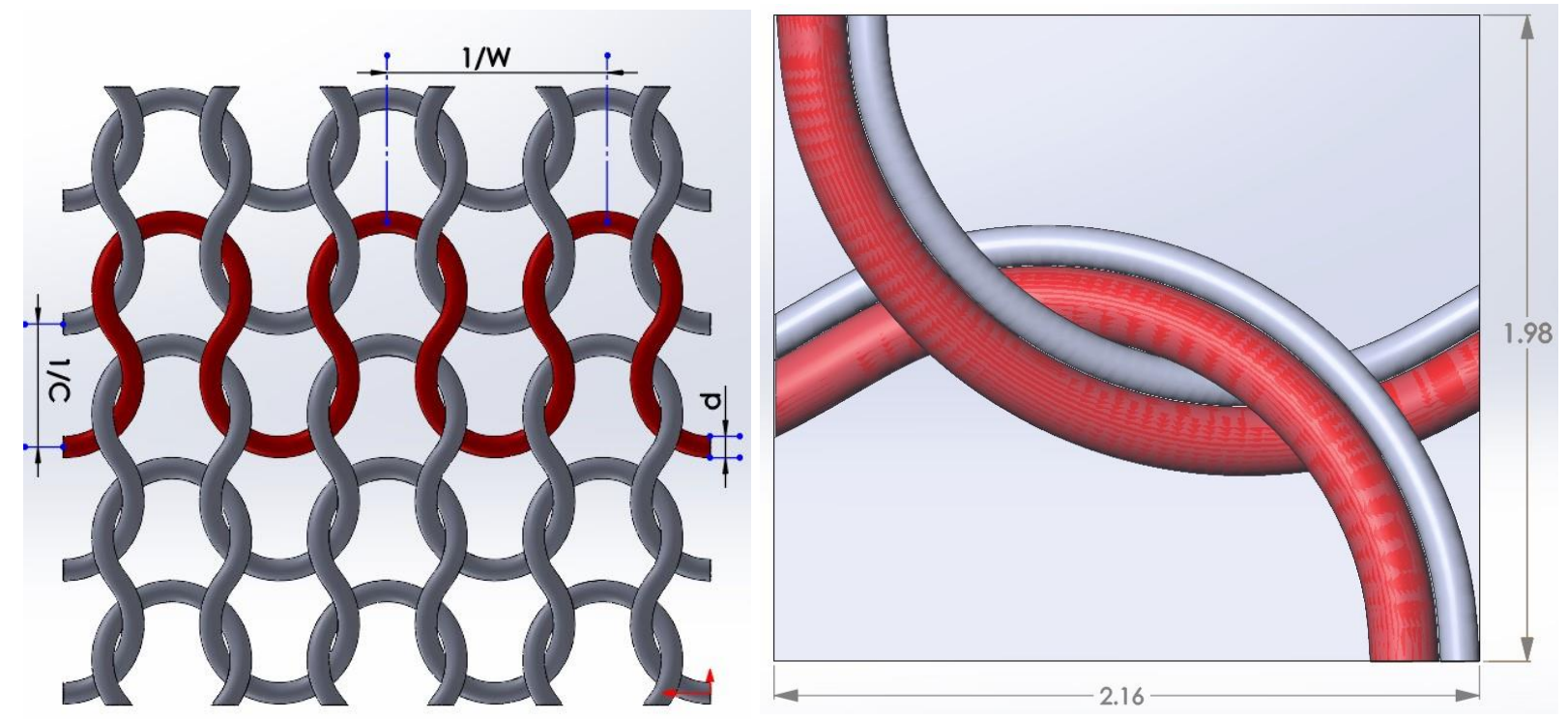

Fig. 1. Knitted fabric geometry (a) and unit cell of model used for simulation (b)

In this research paper, a structural composite unit cell model was geometrically created, meshed and numerically calculated using SolidWorks software for longitude $X$ and transverse $Y$ direction. For obtaining the elastic modulus, three different simulations were carried out using three different models which are Carbon T300 knitted fabric, Alloy steel SY11/1 and hybrid T300 - SY11/1 knitted fabric with epoxy resin as a matrix for all. For the simulation, the thread was considered as a homogeneous elastic rod. The elastic modulus value for our two different reinforcements, Carbon fiber T300 and alloy steel SY11 was taken $230 \mathrm{GPa}$ and $210 \mathrm{GPa}$, respectively. On the other hand, the elastic modulus value for our matrix epoxy resins was selected as $4.0 \mathrm{GPa}$.

Initially, the coordinates $x, y$ and $z$ were obtained for the first and second thread using equations from the Leaf and Glaskin Model [7; 14]. Parameters for the knitted fabric with Carbon T300 fiber are: the wale number $W=2.25$ loops $\cdot \mathrm{cm}^{-1}$, course number $C=5.60$ loops $\cdot \mathrm{cm}^{-1}$ and the thread diameter $=0.022 \mathrm{~cm}$. On the other hand, the parameters for alloy steel SY11/1 knitted fabric are: the wale number $W=2$ loops $\cdot \mathrm{cm}^{-1}$, course number $C=5$ loops $\cdot \mathrm{cm}^{-1}$ and the thread diameter $=0.012 \mathrm{~cm}$. For our Hybrid T300 - SY11/1 model, the parameters $\mathrm{W}=2.5$ loops $\cdot \mathrm{cm}^{-1}$ and $C=5 \mathrm{loops} \cdot \mathrm{cm}^{-1}$ were taken.

3D curve was obtained in Solidworks by inputting $x, y$ and $z$ coordinates for both the thread and later connected by using the Spline function. Thread was simulated as a homogeneous elastic rod using the sweep function that creates a base by moving a profile (diameter of thread in our case) along a spline curve.

After that the extruded cut feature was used to cut down the unnecessary parts for the unit cell study. The matrix of the weft knitted fabric was created as a cube of a thickness covering both threads. To make hollo loop for the thread inside the matrix, the swept cut function was used. Finally, the assembly of the thread and matrix was created in Solidworks Assembly. 
Boundary conditions are a crucial part for accurate result in any numerical simulation. Since both components, the thread and matrix were in constant touch, contact bonded set was applied with no penetration. For the outside surfaces for both studies on longitudinal and transverse direction, the left, down and front face surface of the unit cell was fixed using a roller slider that implies that faces are allowed to move freely into their own plane, but not allowed to move in the direction normal to the plane. For the longitudinal $X$ direction, the surface displacement of $U_{x}=0.001 \mathrm{~mm}$ on the right face normal to the right plane was given, as shown in Fig. 2a, and for the transverse $Y$ direction, displacement of $U_{y}=0.001 \mathrm{~mm}$ on the upper(top) face, normal to the top plane of geometry was applied with restrain to other planes, as shown in Fig 2b. For the front surface $U_{x}=0$, while $U_{y}$ and $U_{z} \neq 0$. For the left surface $U_{y}=0$, while $U_{z}$ and $U_{x} \neq 0$ and for the down surface $U_{z}=0$, while $U_{y}$ and $U_{x} \neq 0$.

a)

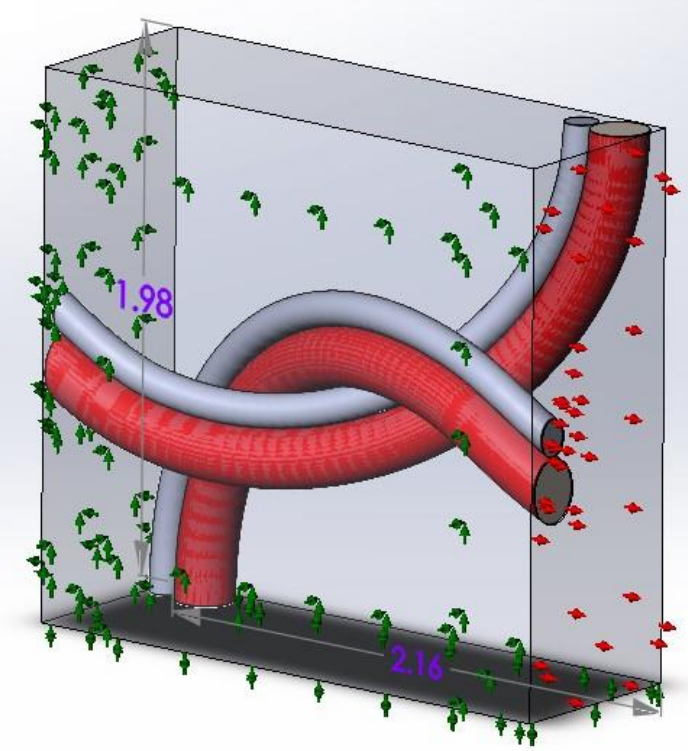

b)

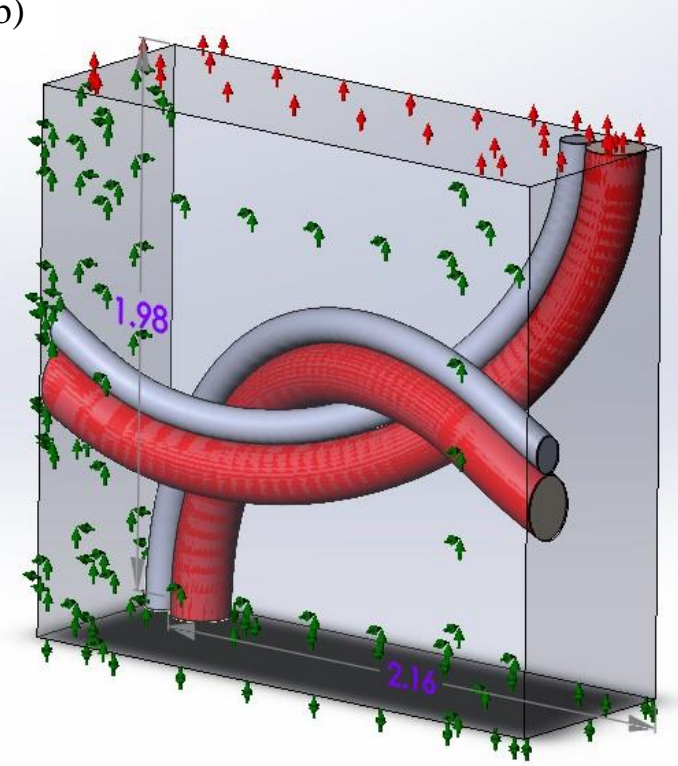

Fig. 2. Boundary condition: $a-$ in longitudinal direction $b-$ in transverse direction

During the simulation, it was noticed that the results of the analysis, especially the stress value, was highly dependable on the chosen mesh size and type. Curvature based mesh was generated with the maximum element size of $0.03 \mathrm{~mm}$. Very fine mesh was generated in order to get accurate results. Fig. 3 shows the model after meshing.

a)

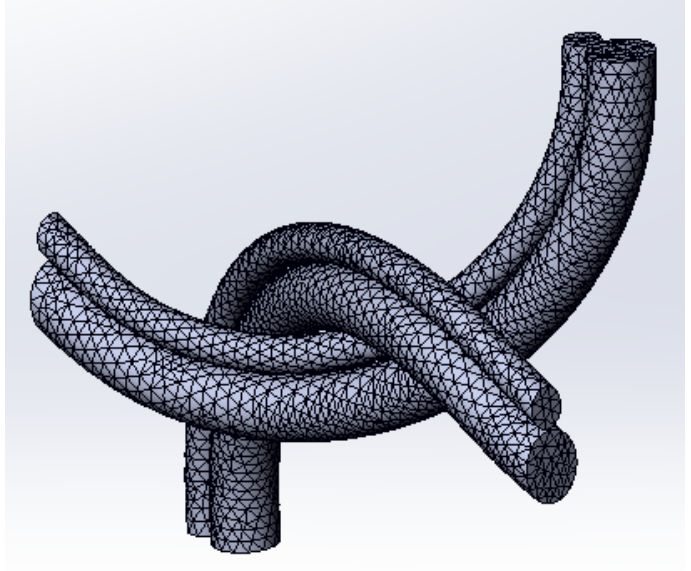

b)

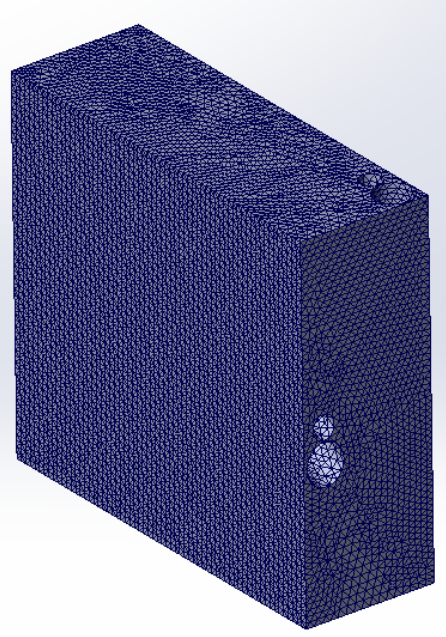

Fig. 3. Applied mesh: $a$ - in fibre $b$ - in matrix 


\section{Results and discussion}

The finite element analysis done on three different models gives an interesting result. The analysis done on the created model of Carbon T300 fiber, SY11/1 alloy steel and hybrid T300-SY11/1 has different results of elastic modulus. To calculate the elastic modulus, the simple Hooke's law was used with the value of stress and strain on longitude and transverse direction taken from Solidworks simulation. The result of Solidworks simulation for longitude and transverse direction is shown in below Figures 3 and 4 . We can also see the boundary conditions of the applied displacement (in red) and roller slider (in green).
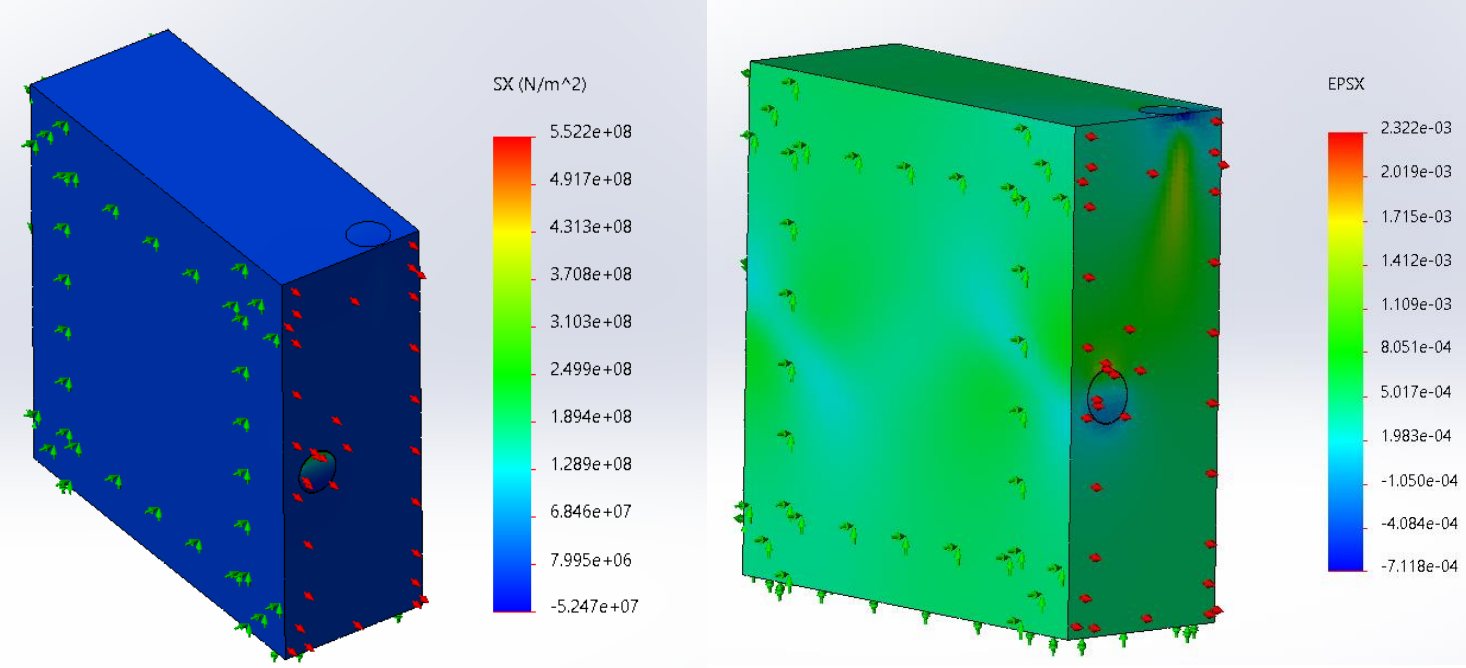

Fig. 3. Strees and strain in longitude direction for T300 Model
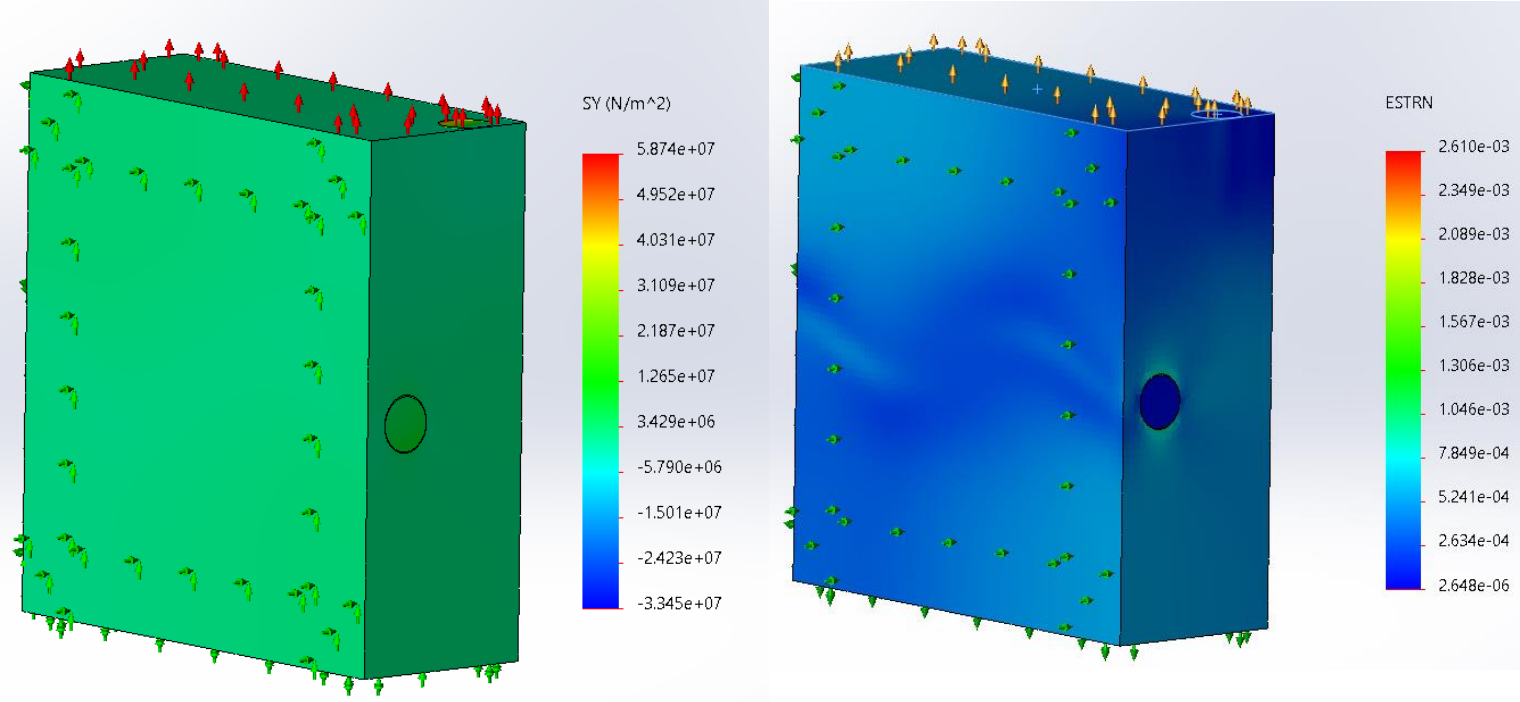

Fig. 4 Stress and strain in transverse direction for T300 Model

Table 1

\section{Result of simulation}

\begin{tabular}{|l|c|c|c|c|}
\hline Model & Direction & \multicolumn{1}{|c|}{${\text { Stress, } \mathbf{N} \cdot \mathbf{m}^{\mathbf{2}}}^{\text {Strain }}$} & Elastic modulus, GPa \\
\hline \multirow{2}{*}{ SY11/1 Alloy steel } & $X$ & $3.043 \mathrm{E}+06$ & $5.000 \mathrm{E}-04$ & 6.09 \\
\cline { 2 - 5 } & $Y$ & $2.565 \mathrm{E}+06$ & $5.000 \mathrm{E}-04$ & 5.13 \\
\hline \multirow{2}{*}{ T300 Carbon } & $X$ & $3.942 \mathrm{E}+06$ & $4.651 \mathrm{E}-04$ & 8.48 \\
\cline { 2 - 5 } & $Y$ & $2.397 \mathrm{E}+06$ & $4.500 \mathrm{E}-04$ & 5.33 \\
\hline \multirow{2}{*}{ Hybrid T300 - SY11/1 } & $X$ & $4.320 \mathrm{E}+06$ & $4.620 \mathrm{E}-04$ & 9.35 \\
\cline { 2 - 5 } & $Y$ & $2.869 \mathrm{E}+06$ & $5.000 \mathrm{E}-04$ & 5.74 \\
\hline
\end{tabular}


The result of the elastic modulus of the three different models from Solidworks is shown in Table 1 for longitudinal $\mathrm{X}$ and transverse $\mathrm{Y}$ direction. T300 Carbon reinforcement has a higher elastic modulus in both directions than the SY11/1 alloy steel. Using the Hybrid T300 - SY11/1 reinforcement can give even a higher value of the elastic modulus, what implies a better load bearing and stress absorbing capacity.

\section{Conclusions}

Geometrical modelling based on the Leaf and Glaskin model was created in Solidwork software and FAE based numerical analysis was done to obtain the elastic properties of knitted fabric. Epoxy resin with the elastic value of 4.0GPa was used and was reinforced by SY11 alloy steel and T300 Carbon fiber. A hybrid reinforcement of both fibers was also created. Results of the elastic properties for the knitted fabric were obtained from the stress and strain value obtained from Solidworks.

The inclusion of reinforced materials in the epoxy matrix can significantly improve the elastic properties and mechanical strength of the material. In this research, inclusion of SY11/1 fibre in epoxy resin matrix improves the elastic modulus from 4.0 GPa to 6.09 $\mathrm{GPa}$ in longitudinal direction. While inclusion of T300 has nearly doubled the elastic modulus of epoxy resins from $4.0 \mathrm{GPa}$ to $8.48 \mathrm{GPa}$. Highest improvements can be seen in Hybrid T300-SY11/1 reinforcement with 9.35GPa. The improved material has a wide range of applications, making it the first choice of materials in many industries. More in-depth research and technological development are crucial to make the material and the process more durable and cost effective.

\section{Acknowledgements}

This work has been supported by the Riga Technical University Doctoral Grant Program.

\section{References}

[1] Lusis V. et al. "Effect of short fibers orientation on mechanical properties of composite material fiber reinforced concrete," J. Civ. Eng. Manag., vol. 23, no. 8, pp. 1091-1099, Nov. 2017, DOI: 10.3846/13923730.2017.1381643.

[2] Kononova O., Lusis V., Galushchak A., Krasnikovs A., MacAnovskis A. "910. Numerical modeling of fiber pull-out micromechanics in concrete matrix composites," J. Vibroengineering, vol. 14, no. 4, 2012, pp. 1852-1861.

[3] Lusis V., Krasnikovs A. "Fiberconcrete with non-homogeneous fibers distribution," in Vide. Tehnologija. Resursi - Environment, Technology, Resources, vol. 2, 2013, pp. 67-71, DOI: 10.17770/etr2013vol2.856.

[4] Macanovskis A., Lukasenoks A., Krasnikovs A., Stonys R., Lusis V. "Composite fibers in concretes with various strengths," ACI Mater. J., vol. 115, no. 5, pp. 647-652, Sep. 2018, DOI: $10.14359 / 51702343$.

[5] Gaidukovs S., Lyashenko I., Rombovska J., Gaidukova G. "Application of amber filler for production of novel polyamide composite fiber," Text. Res. J., vol. 86, no. 20, Dec. 2016, pp. 21272139. DOI: $10.1177 / 0040517515621130$.

[6] Lašenko I., Gaidukovs S., Rombovska J. "Manufacturing of amber particles suitable for composite fibre melt spinning,” Proc. Latv. Acad. Sci. Sect. B Nat. Exact, Appl. Sci., vol. 70, no. 2, Apr. 2016, pp. 51-57. DOI: 10.1515/prolas-2016-0007.

[7] Ramakrishna S., Huang Z. M., Teoh S. H., Tay A. A. O., Chew C. L. "Application of the Model of Leaf and Glaskin to Estimating the 3D Elastic Properties of Knitted-fabric-reinforced Composites," J. Text. Inst., vol. 91, no. 1, 2000, pp. 132-150, DOI: 10.1080/00405000008659494.

[8] Postle R., Munden D. L. "25-Analysis of the dry-relaxed knitted-loop configuration: Part II: Three-dimensional analysis," J. Text. Inst., vol. 58, no. 8, Aug. 1967, pp. 352-365 DOI: $10.1080 / 00405006708629881$.

[9] Vassiliadis S. G., Kallivretaki A. E., Provatidis C. G. "Geometrical modelling of plain weft knitted fabrics," Indian J. Fibre Text. Res., vol. 32, no. 1, Mar. 2007, pp. 62-71.

[10] Choi K. F., lo T. Y. “An Energy Model of Plain Knitted Fabric,” Text. Res. J., vol. 73, no. 8, 2000, pp. 739-748. DOI: 10.1177/004051750307300813. 
[11] Kononova O., Krasnikovs A., Harjkova G., Lusis V. "Numerical simulation of mechanical properties for composite reinforced by knitted fabric," in 11th World Congress on Computational Mechanics, WCCM 2014, 5th European Conference on Computational Mechanics, ECCM 2014 and 6th European Conference on Computational Fluid Dynamics, ECFD 2014, 2014, vol. 5, pp. 2925-2932.

[12] Krasnikovs A., Kononova O., Machanovskis A., Zaharevskis V., Akishins P., Ruchevskis S. "Characterization of mechanical properties by inverse technique for composite reinforced by knitted fabric. Part 2. Experimental evaluation of mechanical properties by frequency eigenvalues method," J. Vibroengineering, vol. 14, no. 2, 2012, pp. 691-698.

[13] Gommers B., Verpoest I., Van Houtte P. "Modelling the elastic properties of knitted-fabricreinforced composites," Compos. Sci. Technol., vol. 56, no. 6, 1996, pp. 685-694. DOI: 10.1016/0266-3538(96)00053-X.

[14] Krasnikovs A., Kononova O., Harjkova G., Zaharevskis V., Galushchak A. "Mechanical properties characterization by inverse technique for composite reinforced by knitted fabric," ECCM 2012 Compos. Venice, Proc. 15th Eur. Conf. Compos. Mater., vol. 14, no. 2, 2012. 